\title{
ETNICIDADE E ENVELHECIMENTO: ESTUDO DE ARTIGOS DE JORNAIS DA COMUNIDADE NIPO-BRASILEIRA
}

Patricia Tamiko Izumi

RESUMO: Análise da imagem dos idosos e as preocupações ligadas ao fenômeno do envelhecimento da comunidade nipo-brasileira, que surgiu a partir da década de 50, e suas transformações, tendo como material os artigos publicados no Jornal Paulista, durante o período de 1952-1997. Além disso, breve apresentação das instituições da comunidade que atendem a questão dos idosos nipo-brasileiros e suas principais atividades de assistência social no Estado de São Paulo.

PALAVRAS-CHAVE: envelhecimento; etnicidade; comunidade nipo-brasileira; Jornal Paulista.

O objetivo deste artigo é apresentar brevemente as instituições da comunidade que atendem a questão dos idosos nipo-brasileiros e suas principais atividades de assistência social no Estado de São Paulo e analisar a imagem dos idosos e as preocupações ligadas com o fenômeno do envelhecimento da comunidade nipobrasileira, que surgiu a partir da década de 50 , e suas transformações, tendo como material os artigos publicados no Jornal Paulista (um dos jornais publicados em língua japonesa) durante o período de 1952-1997.

No período pós-guerra, houve um declínio do movimento imigratório japonês e, em contrapartida, um aumento de problemas resultantes do envelhecimento dos antigos imigrantes. Em São Paulo, a Beneficência Nipo-Brasileira de São Paulo, o Enkyô, é a principal instituição que se preocupa com a questão do envelhecimento. O Enkyô instalou os seguintes estabelecimentos de assistência aos idosos: 
1. Casa de Reabilitação Social de Santos (Santos Kosei Home): resultante da conversão da antiga Casa do Imigrante de Santos. Asilo de idosos fundada em 1971, com regime de internato e capacidade para 60 residentes. Oferece assistência social, médica e odontológica, além de atividades recreativas e ocupacionais;

2. Recanto de Repouso Sakura Home: localizada em Campos do Jordão, a partir de 1965 começou a atender idosos em regime de internato e tem capacidade para 40 residentes que recebem assistência social e médica, e também atividades ocupacionais e de lazer;

3. Casa de Repouso Suzano (Suzano Ipelândia Home): fundada em 1983 na colônia de Fukuhaku, situada a $10 \mathrm{~km}$ da cidade de Suzano. Tem capacidade para oferecer atendimento social e médico e atividades para 30 idosos, em suítes individuais e duplas;

4. Casa de Repouso Akebono: iniciou suas atividades em 2000 com o objetivo de prestar atendimento a idosos dependentes na atividades da vida diário, em regime de residência/abrigo, com capacidade para 50 residentes. Oferece atendimento social e médico com atividades adequadas a esse público.

Além das instituições de longa permanência, o Enkyô dedica atendimento diferenciado aos idosos no seu hospital; promove, juntamente com outras instituições, cursos para cuidadores de idosos, palestras com a participação de profissionais da saúde, gerontologistas e voluntários da JICA.

Outra instituição de grande importância é a organização assistencial mais antiga da colônia, a Assistência Social Dom José Gaspar, que foi dirigida por Margarida Vatanabe, e mantém o asilo Jardim de Idosos São Francisco Xavier (Ikoi no Sono ), desde 1958.

O Ikoi no Sono possui duas alas: a ala para independentes e semidependentes, composta de 54 quartos individuais; e a ala para dependentes, com capacidade para 56 residentes, uma equipe de enfermagem 24 horas, sala de fisioterapia, refeitório e outras instalações adaptadas para os residentes que necessitam de cuidados especiais. A entidade possui atividades técnicoprofissionais, tais como, assistência médica e odontológica, enfermagem e cuidador de idosos, nutrição, fisioterapia, serviço social, psicologia e especialista em assistência ao idoso enviada do Japão pela JICA. Além disso, há atividades de recreação com os residentes, como cerâmica, musicoterapia, karaokê, shodô, jardinagem e festejos.

Antes de analisar os artigos do Jornal Paulista, é importante destacar alguns eventos interessantes ocorridos nesse período estudado. Para isso, foi pesquisada a Cronologia da Imigração Japonesa no Brasil (Centro de Estudos Nipo-Brasileiros, 1996):

- 25/04/1958 - Abertura do Jardim Repouso São Francisco (Ikoi no Sono). O primeiro idoso a ser recebido foi Jingoro Yonamine (71 anos), imigrante vindo no Kasato-maru. 
- 28/02/1967 - A Federação das Associações de Províncias do Japão no Brasil e a Federação da Migração Ultramarina do Japão enviaram ao Japão 9 imigrantes do Kasato-maru, com idade entre 62 e 81 anos.

- 26/09/1972 - Com o avanço da idade dos imigrantes do período anterior à guerra, foi instituída a semana dos Idosos.

- 09/06/1973 - A província de Miyagi, a título de auxílio ao kenjinkai, inicia pagamento de abono velhice aos idosos com mais de 77 anos de idade.

- 15/10/1973 - A província de Fukuoka instituiu mecanismo para convidar imigrantes de sua província com mais de 70 anos de idade que vivem há mais de 30 anos no Brasil.

- 08/08/1975 - Fundada a Associação Brasileira dos Idosos Nikkeis.

- 15/08/1979 - Enkyô tomou a decisão de atender, gratuitamente, os idosos em seu ambulatório.

- 31/07/1980 - 14 imigrantes idosos partem para o Japão pelo programa de convite pela província de Miyagi, inaugurando o programa instituído pelo governo dessa provincia.

- 16/01/1983 - Inaugura-se a casa de repouso para idosos Suzano Ipelândia Home. Trata-se da primeira instituição nikkei do gênero paga.

Como uma etapa da pesquisa, estamos fazendo o levantamento e análise de artigos do Jornal Paulista, no período de 1952-1997, pertencente ao acervo da Biblioteca do Museu Histórico da Imigração Japonesa. O levantamento de notícias está sendo feita através de palavras-chaves relacionadas ao tema envelhecimento, contidas no título da notícia. Neste artigo ainda não foi possível disponibilizar dados quantitativos e nem quais tipos de notícias foram coletadas, pois a coleta ainda não foi finalizada, mas já é possível tecer algumas considerações. Mas antes disso, citaremos um trecho do livro $A$ reinvenção da velhice: socialização e processos de reprivatização do envelhecimento (1999) de Debert, uma das principais especialistas em envelhecimento do Brasil:

"a tendência, de uma maneira geral, é ver a etnicidade como um elemento que transforma a velhice numa experiência bem-sucedida, ou pelo menos num fator mitigador das dificuldades enfrentadas pelos idosos. A etnicidade teria vantagens por razões diversas. É um fator que congrega idosos com a mesma identidade étnica e/ou religiosa, pois oferece uma rede de relações e associações formais e informais independente das relações familiares." (p.91-92)

Esse aspecto da etnicidade é possível notar pelas notícias dos jornais da colônia. $O$ que aparece no jornal é a imagem de uma sociedade que se preocupa com o envelhecimento de sua comunidade, noticiando as casas de repouso existentes, sua estrutura física, seus 
internos, eventos ocorridos. No caso do Ikoi no Sono, ainda há notícias sobre a Margarida Vatanabe, importante figura da assistência social nikkei. A imagem dos idosos é colocada como uma imagem positiva, sendo possível notar pelas muitas notícias dos idosos bemsucedidos; dos centenários ou quase centenários; dos eventos, chamados keirôkai, para homenagear os idosos nikkeis; notícias sobre os nikkeis idosos em outros países e no Japão.

Como o envelhecimento é uma preocupação mundial, o Jornal Paulista também mostra essa preocupação, não só com a comunidade nipo-brasileira, mas também com os nikkeis de outros países. Em 1997, o jornal dedicou uma coluna com o tema: Nikkei kôreisha to sono kea (Idoso nikkei e seus cuidados). Foram 11 artigos dedicados a esse tema em lugares como: Havaí, Argentina, Paraguai, Chicago, Seatle, México, California, São Francisco, Los Angeles. Foram abordadas questões sobre o cuidado ao idoso, da previdência social, questão hospitalar, casa de repouso, trabalho voluntário e família.

Para exemplificar, comentaremos uma notícia do dia 19 de julho de 1997, que faz parte da coluna Doyôrondan (críticas de sábado) de Miyao Susumu, com o título: Kôreika shakai ichijirushii nikkei shakai (Sociedade nikkei notável sociedade envelhecida)

$\mathrm{O}$ autor mostra dados que fundamentam a idéia de que, ultimamente, o envelhecimento da sociedade nikkei tem avançado. Ele analisa a estatística de São Paulo do censo de 1991, onde a estatística sobre a faixa etária dividida por raça tinha a raça amarela, que reune, além dos nikkeis, os coreanos e chineses. A faixa etária com maior número de habitantes da raça amarela é entre 35 a 44 anos. Quando a população, acima de 65 anos de idade ultrapassa $7 \%$ da população total, comumente essa sociedade é chamada de idosa. No caso da totalidade do Brasil, esse percentual é de 4,82\%. O estado de São Paulo está com 4,95\%. A população nikkei com mais de 65 anos de idade é de $9,26 \%$. Na parte urbana é de $9,11 \%$, e no setor rural a porcentagem corresponde a $11,96 \%$. Esta cifra diz quanto o setor rural está abrigando pessoas mais idosas. $\mathrm{O}$ Japão, que é dito como a sociedade ultra-idosa, tem $15 \%$ de população acima de 65 anos de idade. Os nikkeis da zona rural estão próximos da situação no Japão. Então, a preocupação da comunidade nikkei com seus idosos é muito grande. Quem cuidará desses idosos, se eles não tiverem uma pessoa mais jovem para cuidar? Além dos isseis, os nisseis idosos tem aumentado, então os membros da colônia tem que ter subsídios para cuidar de seus idosos, através de assistência social aos idosos, e colaboração de outras instituições da comunidade nikkei.

Este artigo mostra pelos dados quantitativos a situação dos idosos nikkeis em São Paulo, fazendo com que o leitor reflita sobre essa questão, cada vez mais séria para a sociedade nikkei. E como Debert disse, a etnicidade é um elemento que oferece uma rede de relações e associações formais e informais independente das relações familiares, e que por isso faz com que os membros de sua comunidade estudem e façam algo para melhorar a 
sua situação, independente do que a sociedade brasileira faça por todos os idosos residentes no Brasil.

\section{Bibliografia}

ASSISTÊNCIA Social Dom José Gaspar. Relatório da Diretoria: Exercício de 2005. Guarulhos: Assistência Social Dom José Gaspar, 2005.

ASSOCIAÇÃO Brasil-Japão de Pesquisadores; Casa de Repouso Akebono. Ciclo de Palestras - Atuação da Equipe Multiprofissional na Quarta Idade. Caderno de Resumos. São Paulo: Associação Miyagi Kenjin-kai do Brasil, 14/02/2007.

CENTRO de Estudos Nipo-Brasileiros. Cronologia da Imigração Japonesa no Brasil (Edição Aumentada da Obra Elaborada por Tomoo Handa). São Paulo: Centro de Estudos Nipo-Brasileiros, 1996.

DEBERT, Guita Grin. A reinvenção da velhice: socialização e processos de reprivatização do envelhecimento. São Paulo: Edusp, Fapesp, 1999.

JORNAL Paulista. São Paulo, 1952-1997.

JORNAL Paulista. São Paulo, sábado 19 de julho de 1997, Ano 50, No. 12.072, p.1. 